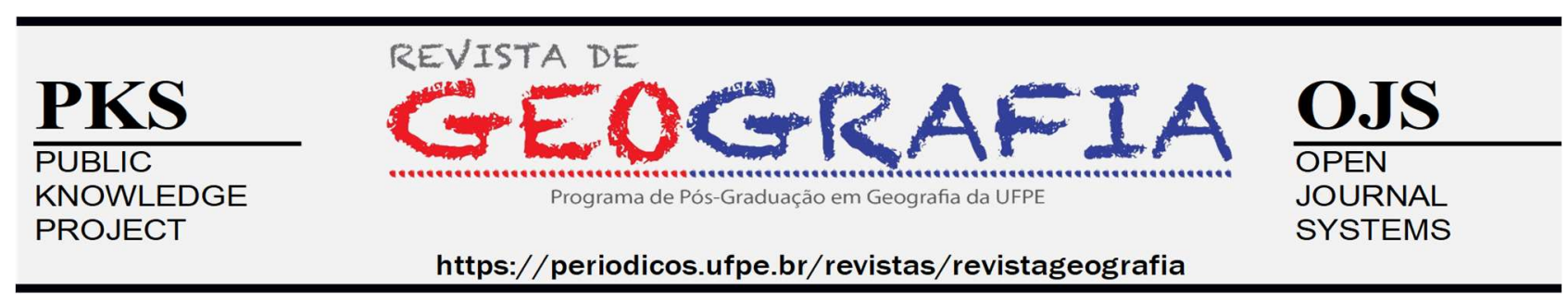

\title{
LICENCIAMENTO AMBIENTAL E OPOSIÇÃO SOCIAL À ENERGIA EÓLICA: ESTUDO DE CASO COM FOCO NO SOCIAL GAP EM COMUNIDADE LITORÂNEA DO CEARÁ, BRASIL
}

\author{
Adryane Gorayeb $^{1}$, Christian Brannstrom ${ }^{2}$ \\ ${ }^{1}$ Professora Doutora do Programa de Pós-Graduaçãoem Geografia da UFC.E-mail: gorayeb@ufc.br \\ ${ }^{2}$ Professor do Departamento de Geografia da Texas A\&M University. Professor Doutor do Programa de Pós- \\ Graduação em Geografia da UFC.E-mail: cbrannst@geos.tamu.edu
}

Artigo recebido em 26/02/2020 e aceito em 16/07/2020

\begin{abstract}
RESUMO
Apresenta estudo realizado sobre a implantação de um parque eólico no litoral oeste do Ceará, analisando como o processo de licenciamento junto ao órgão estadual licenciador acarretou na invisibilização de uma comunidade tradicional situada a 250 metros de distância dos aerogeradores. A oposição da comunidade ao empreendimento está enraizada nas reivindicações pela perda de parte do território tradicional e de seus recursos naturais, especialmente uma lagoa perene utilizada há gerações para pesca e lazer, que foi suprimida durante as obras de construção. Os esforços de mitigação dos impactos capitaneados pelas instituições de assistência social e jurídica, juntamente com o Ministério Público, produziram resultados contraditórios. Falhas no processo de licenciamento ambiental e as consequências dos esforços culminaram em desgastes e conflitos internos, afetando a coletividade em vários níveis. Este trabalho mostra os resultados empíricos obtidos pela pesquisa desenvolvida na perspectiva de análise do conceito social gap, amplamente discutido na literatura internacional, que enfoca a discrepância entre o apoio da opinião pública nacional favorável em contraste à oposição local. A situação exposta provavelmente está presente em outros locais onde existem parques de energia eólica instalados, porém ainda é parcamente relatada na literatura acadêmica nacional.
\end{abstract}

Palavras-chave: Energia eólica; Oposição social; Litoral do nordeste do Brasil; Social gap; Eraser (apagamento cartográfico).

\section{ENVIRONMENTAL LICENSING AND SOCIAL OPPOSITION TO WIND ENERGY: A CASE STUDY OF THE SOCIAL GAP IN THE COASTAL COMMUNITY OF CEARÁ, BRAZIL}

\begin{abstract}
Presents a study about the implantation of a wind park in the west coast of Ceará, analyzing how the licensing process with the state licensing agency resulted in the invisibilization of a traditional community located 250 meters away from the wind turbines. The community's opposition to the investment is based on the demands because of the loss of part of the traditional territory and its natural resources, especially a perennial lagoon used for generations for fishing and recreation, which was suppressed during the construction work. The efforts to mitigate the impacts captained by the social and legal assistance institutions, together with the Public Prosecutor's Office, produced contradictory results. Failures in the environmental licensing process and the consequences of the efforts end up in internal conflicts and animosity, affecting the community at different levels. This work shows the empirical results obtained by the research development from the perspective of the analysis of the social gap concept, widely discussed in international literature, which focuses on the dissonance between the supports of national public opinion in favor of local
\end{abstract}


opposition. The exposed situation is probably present in other places where wind parks are installed, but it is still poorly reported in the national academic literature.

Keywords: Wind energy; Social opposition; Social gap; Erasure; Northeast coast of Brazil.

\section{INTRODUÇÃO}

No Brasil, aproximadamente $26 \%$ da capacidade de energia eólica se desenvolveu na faixa de $5 \mathrm{~km}$ do litoral do nordeste e do sul do país (BRANNSTROM et al., 2018), sendo que a região nordestina corresponde a $85,4 \%$ do montante total de energia gerada por fontes eólicas (ABEEÓLICA, 2020). Isto ocorre em resposta aos subsídios governamentais, à alta qualidade do vento e ao aumento da demanda nacional por eletricidade. A capacidade instalada de energia eólica (11,2 GW) coloca o Brasil como o país líder da América Latina e o oitavo maior do mundo (GLOBAL WIND ENERGY COUNCIL, 2019).

No Estado do Ceará, ocorreram rápidos aumentos de capacidade, saindo de $15 \mathrm{MW}$, em 2002 (ANEEL, 2005), para 1,98 GW, em 2019 (ANEEL, 2019). Todavia, sabe-se que a energia eólica pode atingir no país quase $21 \mathrm{GW}$ (16\% da geração de energia) até 2029, conforme projeções do Ministério das Minas e Energia (BRASIL, 2019).

Ao tentar constituir o cenário que iniciou o processo de implantação e expansão da energia eólica nacional, pode-se dizer que a crise energética de 2001 deu os primeiros passos na formação das bases políticas e econômicas que iriam fundamentar a indústria eólica. A crise foi causada não só em consequência da infraestrutura elétrica obsoleta da nação, como também pelos baixos níveis dos espelhos d'água nos reservatórios que sustentam as usinas hidrelétricas, levando a quedas de energia em escala nacional e a perdas econômicas de aproximadamente 10 bilhões de dólares (TANKHA, 2009).

Em resposta à crise, o governo federal estimulou a construção de parques eólicos por meio da criação de subsídios e programas de estímulo como: leilões liderados pelo Estado, taxas reduzidas de importação, licenciamento simplificado e financiamento pelo Banco Nacional de Desenvolvimento Econômico e Social (BNDES) (FILGUEIRAS; SILVA, 2003; ARAÚJO; FREITAS, 2008; JUÁREZ-HERNANDÉZ; LEÓN, 2014).

$\mathrm{Na}$ urgência de atender a demanda nacional premente e expandir a geração energética com matriz renovável, sem implicações sociais vinculadas às hidrelétricas, a implantação dos parques eólicos foi difundida pelos governos, especialmente o do Nordeste, como utilidade pública na 
perspectiva win-win, ou seja, uma "situação em que todos saem ganhando" (JUÁREZ et al., 2014, p. 833).

Neste contexto, foi elaborada uma literatura oficial derivada dos documentos governamentais, que afirmava que os parques eólicos dividiriam harmoniosamente a terra com as atividades originais da fazenda, enquanto ofereceriam aluguéis aos proprietários (FILGUEIRAS; SILVA, 2003, p. 441), inclusive que a energia eólica seria "praticamente inofensiva" e deveria ser executada com "meios simplificados sem a necessidade de estudos detalhados e demorados de impacto ambiental" (AMARANTE et al., 2001, p. 03).

Em contrapartida, em escala global sabe-se que as análises sobre a oposição às energias renováveis são desiguais, com poucas pesquisas realizadas na América do Sul, África e Ásia, com exceção do sul do México (RUEDA, 2011; JUÁREZ-HERNÁNDEZ et al., 2014; ZÁRATETOLEDO et al., 2019; DUNLAP, 2019; HOWE, 2019; BOYER, 2019). Tal omissão é significativa quando comparada ao potencial global de energia eólica e ao estado do conhecimento sobre conflitos e possíveis resoluções. Portanto, pretende-se contribuir, neste artigo, com análises acerca do social gap da energia eólica no Brasil, em caráter inédito, avançando as pesquisas relacionadas ao tema em países que não estejam na Europa ou na América do Norte.

No contexto brasileiro, as análises geográficas sobre questões energéticas renováveis são preliminares (BRANNSTROM; TRALDI, 2019) e ainda não conseguiram acompanhar o rápido crescimento na capacidade da energia eólica e solar, ambas já instaladas no país (JUÁREZ et al., 2014; AQUILA et al., 2017). No entanto, destacam-se estudos sobre os conflitos sociais gerados entre comunidade e empreendimento eólico (CHAVES et al. 2018; DANTAS et al., 2019; FRATE et al., 2019), assim como as abordagens econômico-políticas dos conflitos (MEIRELES, 2011; BRANNSTROM et al., 2017; GORAYEB et al., 2018) e a justificativa das localizações geográficas dos parques eólicos (BRANNSTROM et al., 2018).

Os enfoques geográficos das pesquisas sobre a expansão eólica nacional podem basear-se nos seguintes fatores: (i) baixa densidade energética, em termos de watts produzidos por quilômetro quadrado, o que requer vastas extensões de terra (SCHEIDEL; SORMAN, 2012; CAPELLÁN-PÉREZ et al., 2017; MILLER; KEITH, 2018; MILLER; KEITH, 2019); (ii) discursos que a indústria eólica cria e reproduz sobre energia "limpa" e compatível com outras atividades (FILGUEIRAS; SILVA, 2003, p. 441); (iii) sobreposição geográfica de locais com alto potencial eólico (AMARANTE et al., 2001; DE JONG et al., 2016); e, (iv) impactos da instalação e presença dos parques eólicos sobre os modos de vida das comunidades tradicionais e o meio 
natural, sobretudo em regiões sem segurança fundiária e áreas de proteção ambiental ou com alto valor ambiental, no litoral e no bioma Caatinga, em especial do interior da Bahia (MEIRELES, 2011; BRANNSTROM et al., 2017; GORAYEB; BRANNSTROM; MEIRELES, 2019; NERI et al., 2019; TRALDI, 2019).

Entender tais contradições no espaço geográfico, visando uma descarbonização com justiça (MULVANEY, 2019), seria um dos objetivos dos estudos geográficos sobre as energias renováveis. Uma sugestão seria a utilização de estudos de caso para auxiliar geógrafos a construírem sínteses sobre os processos emergentes originados a partir da implantação de projetos desta natureza. Entretanto, o cenário criado nos planos governamentais diverge, em muitos casos, da realidade vivenciada no território, situação que pode ser percebida na Praia de Xavier, no Município de Camocim, litoral oeste do Ceará, que sofreu processo de invisibilização devido à construção de um parque eólico, localizado a 250 metros das residências, em ambiente de praia, com lagoas de água doce e dunas móveis.

O processo tornou os moradores "ocultos" aos tomadores de decisão, que forneceram as aprovações estaduais necessárias para o empreendimento. A oposição social nessa situação estava enraizada nas reivindicações pela perda de parte do território tradicional, de seus recursos naturais e infraestrutura, especialmente uma lagoa perene, nomeada de Lagoa do Ferreira, utilizada há gerações para pesca e lazer, que foi suprimida durante as obras de construção, bem como na proibição do uso da estrada interna do parque eólico (reformada pela empresa) que permitia o acesso às casas dos moradores que residiam nas vizinhanças. O caso Xavier evidencia o social gap como resultado do licenciamento ambiental que conduz à marginalização.

Os esforços de mitigação dos impactos, capitaneados pelas instituições de assistência social e jurídica da comunidade, juntamente com o Ministério Público, produziram resultados contraditórios devido à ausência de planejamento e gestão adequados dos gastos do montante adquirido. A situação exposta na pesquisa realizada provavelmente está presente em muitos outros locais que têm presença de energia eólica no país. Todavia, ainda é parcamente relatada na literatura acadêmica nacional. Assim, o artigo se propõe a analisar as falhas no processo de licenciamento ambiental que permitiram a instalação do parque eólico na Praia de Xavier, bem como as consequências dos esforços de mitigação, que resultaram em desgastes e conflitos internos que afetaram a comunidade em vários níveis. 


\section{BASES TEÓRICAS DO SOCIAL GAP NO CONTEXTO DA ENERGIA EÓLICA}

As respostas sociais e políticas ao desenvolvimento da energia eólica onshore são altamente variáveis em nível mundial. Numerosos casos de oposição à energia produzida pelo vento na América do Norte e na Europa fornecem evidências de persistência do social gap, definido como a diferença entre a opinião pública nacional favorável à energia eólica, em contradição à oposição da percepção local que, muitas vezes, resulta em projetos cancelados (BELL et al., 2005; BELL et al., 2013).

Em muitos casos, o conflito é resultado da "imposição" (PASQUALETTI, 2011a; PASQUALETTI, 2011b), quando os empreendedores e o governo priorizam questões técnicas de eficiência e qualidade dos ventos acima dos impasses sociais como: o apego humano ao local, a identidade e a subjetividade em relação às paisagens, e a interrupção dos meios tradicionais e étnicos de subsistência fundamentados nos recursos naturais do território, situação comumente vivenciada no nordeste brasileiro. A literatura internacional caminha no sentido de priorizar os enfoques que abandonaram a descrição simplista "não-em-meu-quintal" (not in my backyard ou NIMBY) da oposição, em favor da postura de complex, multidimensional nature of forces shaping public perception (DEVINE-WRIGHT, 2005, p. 134).

Outra síntese, formulada na América do Norte, argumenta que questões relacionadas à justiça, participação e confiança entre as partes durante o desenvolvimento de um parque eólico são determinantes na aceitação social do empreendimento (RAND; HOEN, 2017). Os autores de base acadêmica anglo-saxã sumarizam vários fatores que a bibliografia aponta como "aceitação" ou "rejeição". Acredita-se ser interessante trazer as análises divulgadas (Quadro 1), uma vez que as pesquisas desenvolvidas nos Estados Unidos e Canadá trazem, em termos globais, os enfoques mais aprofundados em relação aos impactos sociais da energia eólica.

Quadro 1 - Síntese dos resultados de pesquisa sobre os Estados Unidos e o Canadá quanto à aceitação social da energia eólica.

\begin{tabular}{|l|l|}
\hline \multicolumn{1}{|c|}{ Impacto econômico } & \multicolumn{1}{c|}{ Síntese } \\
\hline Desenvolvimento econômico rural & $\begin{array}{l}\text { Criação de emprego; } \\
\text { Melhorar a economia rural. }\end{array}$ \\
\hline Impactos tributários locais & Aumentar a arrecadação tributária. \\
\hline Turismo & Aumentar (ou reduzir) o turismo. \\
\hline Taxa de eletricidade & $\begin{array}{l}\text { Os parques eólicos não conseguem reduzir as taxas } \\
\text { locais. }\end{array}$ \\
\hline Benefícios financeiros aos proprietários ou à & Os proprietários privados de terras com aerogeradores \\
\hline
\end{tabular}




\begin{tabular}{|l|l|}
\hline comunidade & $\begin{array}{l}\text { instalados recebem aluguéis ou royalties, porém, esta } \\
\text { situação também pode gerar conflitos. Diminui-se a } \\
\text { possibilidade de conflitos quando a comunidade recebe } \\
\text { recursos financeiros por meio de associações ou figuras } \\
\text { jurídicas coletivas. }\end{array}$ \\
\hline Oportunidades para investimento local & $\begin{array}{l}\text { É muito raro observar nos EUA e no Canadá a } \\
\text { propriedade coletiva de parques eólicos por meio de } \\
\text { associações, por exemplo. Em geral, prevalecem os } \\
\text { proprietários privados (grandes empresas multina- } \\
\text { cionais de capital misto). }\end{array}$ \\
\hline Impactos na política tributária imobiliária & $\begin{array}{l}\text { Existe a possibilidade de o valor imobiliário ser } \\
\text { reduzido pela proximidade ao parque eólico. }\end{array}$ \\
\hline Justiça distributiva e desigualdade & $\begin{array}{l}\text { Os residentes locais podem sentir-se explorados pelos } \\
\text { parques eólicos. Os benefícios podem ser distribuídos } \\
\text { desigualmente. }\end{array}$ \\
\hline
\end{tabular}

Fonte: RAND; HOEN (2017).

Os fatores institucionais, principalmente a participação pública nos processos de tomada de decisão, ajudam a formar percepções sociais do desenvolvimento da energia eólica (WARREN et al., 2005; WOLSINK, 2007; BREUKERS \& WOLSINK, 2007; TOKE et al., 2008). A apropriação local, por meio de cooperativas ou outras instituições, leva a uma maior aceitação social da energia eólica (WARREN; MCFAYDEN, 2010; WOLSINK; BREUKERS, 2010).

As razões econômicas podem apoiar as percepções sociais. Neste sentido, o pagamento de royalties, os arrendamentos e os aluguéis auxiliam na aceitação da implantação dos parques eólicos, principalmente dos residentes de áreas economicamente desfavorecidas (HORST, 2007; TOKE et al., 2008; DEVINE-WRIGHT; HOWES, 2010). Por outro lado, em Ontário, no Canadá, o processo de implantação tecnocrática denominado "decidir-anunciar-defender" (BAXTER et al., 2013, p. 942) ajudou a produzir conflitos nas comunidades que hospedam parques eólicos (WALKER et al., 2014; SHAW et al., 2015; FAST, 2015; FAST et al., 2016).

Outra perspectiva dominante na bibliografia prioriza a justiça distributiva e a justiça processual, enfocando em como o poder, o conhecimento e os recursos financeiros são distribuídos ao longo do processo de planejamento e licenciamento (BREUKERS; WOLSINK, 2007). Por exemplo, pesquisas revelam que a aceitação desse tipo de empreendimento aumenta quando as pessoas têm um papel no processo decisório, o que seria justiça processual. A questão de justiça no planejamento e no licenciamento (justiça processual) e a distribuição dos benefícios e malefícios (justiça distributiva) estão sendo discutidas em vários trabalhos sobre a problemática no Canadá (WALKER; BAXTER, 2017a; WALKER; BAXTER, 2017b), como podemos observar a seguir no Quadro 2. 
Quadro 2 - Síntese dos assuntos e variáveis considerados na bibliografia sobre a justiça e os parques eólicos.

\begin{tabular}{|l|l|l|}
\hline Conceito de justiça & \multicolumn{1}{|c|}{ Aplicação aos parques eólicos } & \multicolumn{1}{c|}{ Variáveis } \\
\hline \multirow{5}{*}{ Justiça distributiva } & $\begin{array}{l}\text { Quem recebe os impactos nega- } \\
\text { tivos? } \\
\text { Quem recebe os benefícios? }\end{array}$ & $\begin{array}{l}\text { - Distribuição de aluguéis e royalties; } \\
\text { - Empregos diretos e indiretos; } \\
\text { - - Barulhoção do empreendimento; } \\
\text { - Trânsito durante a construção; } \\
\text { - Mitigação por recursos financeiros ou } \\
\text { obras. }\end{array}$ \\
\hline \multirow{5}{*}{ Justiça Processual } & $\begin{array}{l}\text { Quem participa na tomada de } \\
\text { decisões? } \\
\text { Quem determina as regras? } \\
\text { Quais pessoas têm poder para } \\
\text { participar e tomar as decisões? }\end{array}$ & $\begin{array}{l}\text { - Oportunidade para dialogar; } \\
\text { - Relações sobre o empreendedor; } \\
\text { - Possibilidade de influenciar no resul- } \\
\text { tado final. }\end{array}$ \\
\hline
\end{tabular}

Fonte: Sovacool et al. (2016); Walker \& Baxter (2017a); Walker \& Baxter (2017b); Liebe; Bartczak; Meyerhoff (2017).

Sovacool (2009, p. 4511) destaca a existência de uma teia perniciosa (pernicious tangle) de obstáculos econômicos, políticos e comportamentais que impedem a "aceitação social" das energias renováveis. Em outro trabalho, Sovacool e Ratan (2012) sintetizaram as experiências de aceitação das energias renováveis nas dimensões: sociopolítica, empresarial (mercado) e comunitária (Quadro 3).

Quadro 3 - As dimensões da aceitação social, política, empresarial e comunitária da energia renovável.

\begin{tabular}{|c|l|l|}
\hline Dimensão & \multicolumn{1}{|c|}{ Critério } & \multicolumn{1}{c|}{ Descrição } \\
\hline Sociopolítica & $\begin{array}{l}\text { Capacidade institucional } \\
\text { Compromisso político } \\
\text { Marco legal favorável }\end{array}$ & $\begin{array}{l}\text { Forte apoio institucional. As lideranças políticas } \\
\text { promovem as energias renováveis. O marco legal facilita } \\
\text { as energias renováveis. }\end{array}$ \\
\hline $\begin{array}{c}\text { Empresarial } \\
\text { (mercado) }\end{array}$ & $\begin{array}{l}\text { Custo de construção com- } \\
\text { petitivo } \\
\text { Acesso à informação } \\
\text { Acesso ao crédito }\end{array}$ & $\begin{array}{l}\text { A base industrial, os incentivos governamentais e os } \\
\text { recursos naturais podem apoiar as energias renováveis. } \\
\text { Os empreendedores precisam ter acesso às informações } \\
\text { sobre o setor energético. O financiamento é necessário. }\end{array}$ \\
\hline Comunitária & $\begin{array}{l}\text { Uso e controle comunitário } \\
\text { Processo participativo de } \\
\text { licenciamento } \\
\text { Imagem pública positiva }\end{array}$ & $\begin{array}{l}\text { Precisa ocorrer participação no processo de licencia- } \\
\text { mento pelos residentes próximos aos empreendimentos. } \\
\text { Os residentes podem ajudar a criar uma imagem positiva. }\end{array}$ \\
\hline
\end{tabular}

Fonte: Sovacool; Ratan (2012).

Um importante instrumento legal de apoio ao conceito de "decidir-anunciar-defender" (BAXTER et al., 2013, p. 942) é o Relatório Ambiental Simplificado (RAS). Idealizado pelo Conselho Nacional do Meio Ambiente (CONAMA), na Resolução ${ }^{\circ}$ 279, de 27 de junho de 
2001, o instrumento jurídico considerava de baixo impacto ambiental empreendimentos como parques eólicos e outros projetos de energia renovável (BRASIL, 2001).

A crise elétrica do Brasil em 2001 forneceu ambiente para que os políticos instituíssem um procedimento simplificado para o licenciamento ambiental, acelerando a geração de energia (JUÁREZ et al., 2014). Os investidores precisavam apenas apresentar o RAS que, basicamente, incluía uma declaração do engenheiro responsável afirmando que o projeto tinha baixo potencial de impacto ambiental. Na mesma resolução foi imposto um período máximo de 60 (sessenta) dias para licenciar os projetos considerados necessários para aumentar o suprimento de eletricidade no Brasil.

Notavelmente, o RAS sobreviveu à crise elétrica. Contudo, em 2014 o CONAMA emitiu a exigência de que seria necessário realizar um Estudo de Impacto Ambiental (EIA) apenas se os parques eólicos fossem implementados em ambientes "frágeis", como campos de dunas e manguezais, ou se os parques eólicos exigissem que as comunidades nas circunvizinhanças fossem realocadas (BRASIL, 2014).

A partir da literatura pesquisada para a elaboração deste artigo, supomos que no Brasil o social gap seja produto da sobreposição de fatores técnicos relativos aos parques eólicos (presença de ventos atraentes, baixa densidade energética e demanda por grandes extensões de terras) aliados à existência de comunidades tradicionais que têm sido marginalizadas ao longo da história pelo poder público (pescadores artesanais, agricultores, camponeses, quilombolas e indígenas) (MEIRELES, 2011; BRANNSTROM et al., 2017; GORAYEB, 2018). Analisamos, ainda, o papel de um fator institucional - o processo de licenciamento ambiental - que aprofunda o social gap no nordeste brasileiro.

\section{METODOLOGIA E LOCALIZAÇÃO DA ÁREA DE ESTUDO}

Os resultados desta pesquisa têm como base dezenas de trabalhos de campo, elaborados no período de 2011 a 2019, em uma comunidade do litoral oeste cearense, que dista $355 \mathrm{~km}$ de Fortaleza, onde está instalado um parque eólico de 104 MW e 50 turbinas (Figura 1). O parque começou a operar em agosto de 2009 e, na época, tinha a capacidade de suprir 7\% da demanda de eletricidade do Estado.

A comunidade de pescadores tradicionais, conhecida como Xavier, é um assentamento tradicional de 22 famílias (66 residentes) que dependem da pesca com barcos não motorizados (à 
vela ou remo), coleta de mariscos, crustáceos e agricultura em pequena escala. Não existe infraestrutura de turismo presente.

Figura 1 - Localização geográfica da Praia de Xavier, Camocim (CE), Brasil.
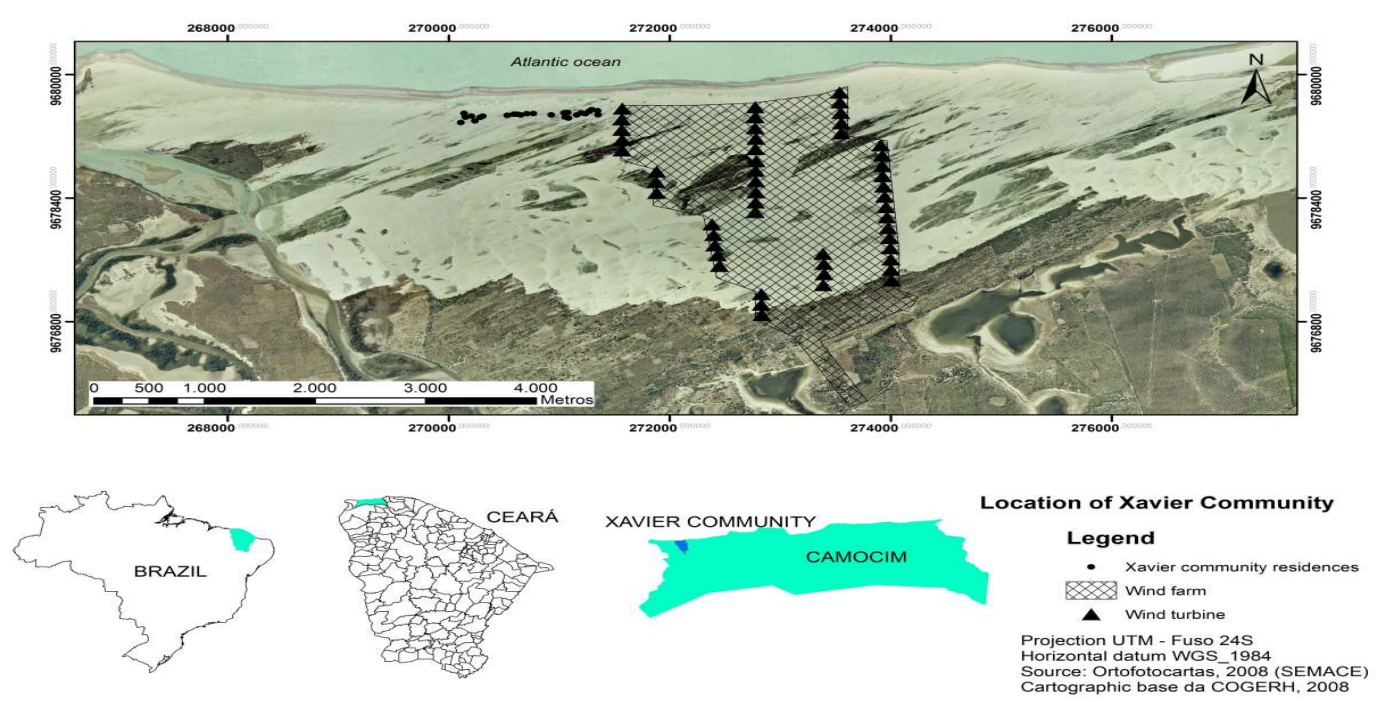

Fonte: Mendes; Gorayeb; Brannstrom (2016).

A pesquisa em Xavier incluiu várias atividades com interação direta da comunidade, como observação participante, oficinas em grupo, caminhadas transversais, construção de uma matriz potencial-problema e discussão coletiva sobre o planejamento do uso da terra, além de uma pesquisa estruturada e análise de materiais textuais.

As atividades foram realizadas semestralmente, no período de oito anos (2011 a 2019), com foco nos moradores membros da Associação Comunitária local. O perfil dos participantes era diversificado, e a cada trabalho de campo, cerca de quinze pessoas (homens, mulheres e crianças) participavam das ações da pesquisa.

As anotações de campo e as gravações das entrevistas foram transcritas e organizadas de acordo com os principais temas emergentes. Os trabalhos de campo participativos forneceram o conhecimento para analisar os documentos contidos no processo de licenciamento do Relatório Ambiental Simplificado (RAS), obtido na biblioteca da Superintendência Estadual do Meio Ambiente do Ceará (SEMACE), localizada em Fortaleza.

A pesquisa foi desenvolvida de modo transversal durante a orientação de trabalhos acadêmicos $^{1}$, o desenvolvimento de ações de extensão universitária ${ }^{2}$ e a elaboração de

\footnotetext{
${ }^{1}$ Trabalhos de conclusão de curso apresentados e publicados no Repositório Institucional da Universidade Federal do Ceará - UFC (MENDES, J. S. Parques eólicos e comunidades tradicionais no Nordeste brasileiro: estudo de caso da Comunidade de Xavier,
} 
documentários $^{3}$. Devido a este perfil multifacetado, pode-se afirmar que os resultados expostos refletem análises e reflexões de quase uma década acerca dos empreendimentos de energia eólica e a conservação das tradições e dos modos de vida de comunidades pesqueiras do litoral do Ceará.

\section{OPOSIÇÃo SOCIAL À ENERGIA EÓlICA: ESTUdO DE CASO NA PRAIA DE XAVIER}

O estado do Ceará, notoriamente, careceu de infraestrutura, informações e controles burocráticos que reduziriam os abusos acometidos no regime de licenciamento ambiental de parques eólicos com base no RAS, em especial no período de 2008 a 2014. Por exemplo, o proprietário da maior empresa de consultoria ambiental contratada por companhias de energia eólica no Estado produzia, à época, 50\% dos RAS (ARAÚJO, 2015). Sendo que o proprietário desta empresa foi condenado, em 2014, a 32 anos de prisão por ter produzido estudos de impacto ambiental enviesados, potencialmente corrompidos e sem rigor técnico (SOBRAL, 2014).

Além disso, a demarcação de terras federais e privadas no litoral do Ceará nunca foi realizada, criando insegurança de posse da terra para as comunidades tradicionais. Tais fraquezas institucionais existem em um contexto no qual quase $90 \%$ da capacidade instalada de energia eólica do Ceará está situada em até $10 \mathrm{~km}$ de distância do litoral, a procura de ventos de alta qualidade (BRANNSTROM et al., 2018; CAMARGO SCHUBERT ENGENHEIROS ASSOCIADOS, 2019). Todavia, o litoral cearense, que abriga praias, campos de dunas, lagoas de água doce e manguezais, é também local de habitação de comunidades tradicionais, que se dedicam à pesca artesanal, mariscagem e à agricultura de pequena escala, muitas vezes, sem consentimento formal ou título legal de posse de terra.

\footnotetext{
litoral oeste do Ceará, por meio da abordagem ecológica/participativa. 2016. 160 f. Tese (Doutorado em Geografia) -Universidade Federal do Ceará, Fortaleza, 2016. (http://www.repositorio.ufc.br/handle/riufc/22807); TAVARES, G. U. Impactos socioambientais na geração de energia eólica: supressão de lagoas interdunares e insegurança alimentar na comunidade de Xavier, Camocim, Ceará. 2018. 27f. Artigo. (Bacharelado em Geografia) - Universidade Federal do Ceará, Fortaleza, 2018. (http://www.repositorio.ufc.br/handle/riufc/35678); SILVA, L. N. A. Paisagem sonora e análise dos impactos causados por ruídos em parques eólicos na comunidade Xavier, Camocim, litoral oeste do Ceará. 2019. 86 f. Dissertação (Mestrado em Geografia) - Universidade Federal do Ceará, Fortaleza, 2019. (http://www.repositorio.ufc.br/handle/riufc/40937); LEITE, N. S. Respostas de comunidades ao desenvolvimento da energia eólica no litoral do Ceará, Brasil. 2019. 252 f. Tese (Doutorado em Geografia) - Universidade Federal do Ceará, Fortaleza, 2020. (http://www.repositorio.ufc.br/handle/riufc/51038)

${ }^{2}$ Artigos relatando experiências dos trabalhos publicados na obra: GORAYEB, A.; Meireles, A. J. A.; SILVA, E. V. (org.). Cartografia social e cidadania: experiências de mapeamento participativo dos territórios de comunidades urbanas e tradicionais. Fortaleza: Expressão $\quad$ Gráfica, $2015 . \quad 196 \mathrm{p} . \quad$ Disponível em: https://drive.google.com/file/d/17cYcmG1e8v911Hcub2THVj1wOLwKYoB4/view

${ }^{3}$ GORAYEB, A. et al. JLAG Perspectives: videography for participatory cartography in a site of wind power conflict in Coastal Ceará State, Brazil. J. Lat. Am. Geogr., v. 16, n. 3, 2017, p. 159-163. DOI:10.1353/lag.2017.0049.
} 
Em relação ao processo de elaboração do RAS, os moradores da Praia de Xavier não tiveram acesso a informações preliminares sobre a construção do parque eólico, embora isso seja exigido por lei (BRASIL, 2001). Segundo os moradores, a equipe técnica da empresa começou a inspecionar as residências em 2005, logo após o governo estadual instalar um anemômetro a 20 km de Xavier (MEIRELES et al., 2013). A comunidade não recebeu nenhum benefício ou compensação financeira do empreendimento até 2014 (aluguéis, royalties ou serviços sociais), ainda que a falta de perícia técnica durante a construção do parque eólico tenha extinguido a maior lagoa de água doce da região e única perene, a Lagoa do Ferreira, utilizada para a pesca e o lazer há décadas pelos moradores.

Atualmente, a comunidade enfrenta um deficit alimentar devido à impossibilidade da pesca lacustre. Outros problemas surgiram durante e após o processo de construção do parque eólico, como o bloqueio do acesso à comunidade pela empresa, que dispunha da única via transitável do local, e o medo constante dos moradores devido à explosão de uma turbina (MENDES; GORAYEB; BRANNSTROM, 2016). A seguir, serão discutidos eventos e processos que incentivaram esses conflitos.

\section{Invisibilização física e cartográfica da Praia de Xavier}

A invisibilização cartográfica em Xavier foi concretizada e é aparente em um mapa de 2002 contido no RAS do empreendimento. A cartografia apresenta vários erros e omissões técnicas, sendo mais flagrante o fato de a comunidade de 22 casas da Praia de Xavier não ter sido retratada nele. A Figura 2 compara o mapa do RAS com a disposição da locação das torres, com o que, de fato, foi construído sobre as dunas móveis a 250 metros do perímetro de habitação. 
Figura 2 - Comparação entre o mapa incluído no RAS (à esquerda) e a disposição real das turbinas no terreno da Praia de Xavier, Camocim (CE) (à direita).

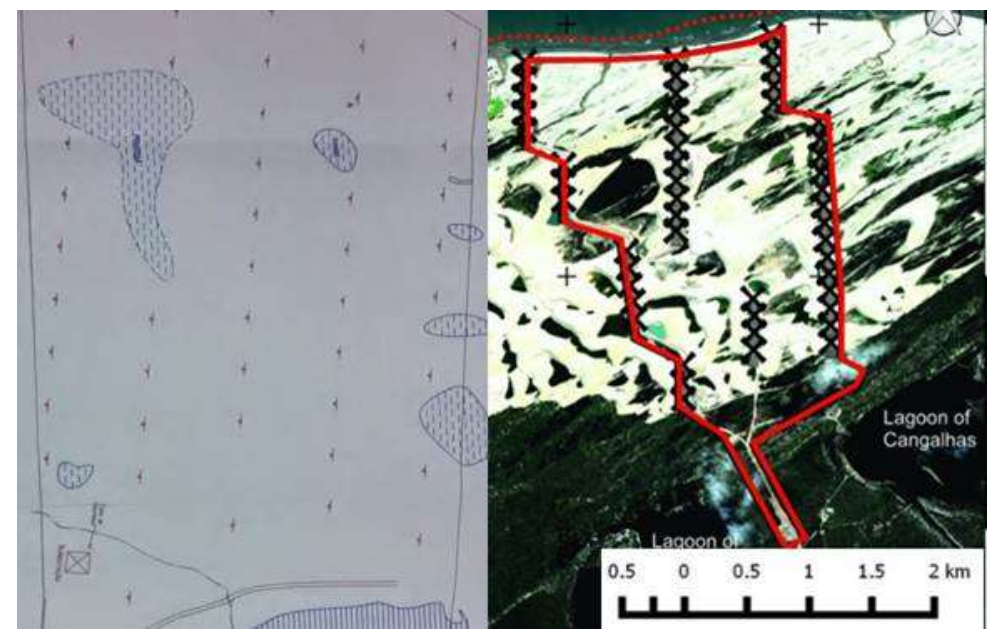

Fonte: Relatório Ambiental Simplificado - RAS (GEOCONSULT, 2002), do Parque Eólico Praia Formosa, à esquerda, e imagem de satélite Quickbird, 2010 (SEMACE), à direita.

Apenas 250 metros separam a casa mais próxima de uma turbina eólica, dificultando a compreensão de como os técnicos da consultora ambiental responsável pelo RAS poderiam ter ignorado a comunidade de Xavier. Sem a presença de pessoas no mapa, os tomadores de decisão, em particular os funcionários do órgão de licenciamento ambiental, não observaram o impacto social iminente e não executaram os procedimentos legais que, na prática, atrasariam o licenciamento do parque eólico.

Após o "apagamento cartográfico" (eraser, termo utilizado na literatura científica anglofônica) dos moradores de Xavier, os documentos do RAS criaram um novo nome para a praia, descrevendo-a e a área das dunas como "Praia Formosa". O "apagamento da identidade" comunitária removeu o nome tradicional "Praia de Xavier", culturalmente aceito, socialmente difundido e presente nos documentos oficiais (municipais e estaduais) anteriores à implantação do empreendimento, como em mapas turísticos, documentos oficiais posteriores, etc. Durante o licenciamento do parque, os governos estaduais e municipais incorporaram o nome da praia dada pelo projeto privado em documentos oficiais, completando o "apagamento das pessoas" e ocultando a vasta história de vida de dezenas de cidadãos cearenses.

É importante ressaltar que os terrenos utilizados para a implantação do parque eólico não eram usufruídos por entes particulares até a construção da obra. Seu uso social e ambiental era considerado de grande valor, uma vez que parte deles é de área de praia, parte de dunas móveis e 
dunas fixas, com disposição de dezenas de lagoas de água doce, utilizadas diariamente por uma população de pescadores tradicionais por, pelo menos, três gerações ${ }^{4}$.

O subitem do RAS intitulado "Área do Projeto" afirma que o campo de dunas é propriedade privada, garantida por arrendamento entre a empresa e um proprietário de terras privado. Ao apresentar às autoridades estaduais evidências de um contrato de aluguel, o RAS apaga a ocupação contínua do campo de dunas pela comunidade residente da Praia de Xavier. Para um analista escrupuloso, a existência de uma reivindicação de arrendamento de terras em um campo de dunas indica a privatização clandestina de um recurso comum e transferência fraudulenta de terras.

Entre os muitos erros cometidos pelo RAS, que causaram a invisibilização dos moradores de Xavier e a exclusão de feições ambientais relevantes nos mapas, destacam-se: (i) o número de lagoas interdunares mapeadas não corresponde ao número real; (ii) a localização das turbinas eólicas não tem relação com a topografia do campo de dunas; (iii) não há curvas de nível e não foi feito levantamento topográfico da área, informação primária nesses tipos de estudo; (iv) o número de turbinas indicado não corresponde ao número de turbinas instaladas; (v) a área real do parque eólico é quase o dobro da área mapeada no RAS. Essas omissões parecem ter sido planejadas para acelerar os processos de aprovação do licenciamento junto ao órgão responsável do Estado, a SEMACE (Superintendência Estadual do Meio Ambiente). Entretanto, os moradores vivenciaram efeitos nefastos, permeados por graves impactos ambientais negativos e conflitos.

Além disso, a narrativa do discurso contido na construção textual do RAS contém numerosos erros técnicos. Por exemplo, conforme o RAS, a área de dunas é caracterizada por um relevo plano adequado à construção do parque eólico quando, na verdade, as dunas atingem até 40 metros de altitude. Em outro trecho, o RAS afirma que a infraestrutura existente próxima ao parque é a rodovia estadual CE-040 que, na realidade, está a mais de $300 \mathrm{~km}$ de distância da área. Como demonstramos, o topônimo "Xavier" está ausente do documento e o texto menciona que a única "comunidade significativa existente é Amarelas", que é a sede do distrito e fica a 1,5 km da comunidade de Xavier e da entrada do parque, com uma população total estimada em 650 pessoas.

As autoridades municipais produziram documentos incluídos no RAS que apoiam o “apagamento cartográfico", sugerindo que as elites locais, pessoas envolvidas com os governos estadual e municipal foram cúmplices do apagamento. Em um documento emitido pela Secretaria

\footnotetext{
${ }^{4}$ Para maiores esclarecimentos acerca do uso tradicional da terra e dos recursos naturais pela população de pescadores tradicionais da Praia de Xavier, assistir ao documentário: "Nosso mapa foi nós que fizemos": território, cartografia social e energia eólica no litoral oeste do Ceará. Disponível em: https://www.youtube.com/watch?v=r5aI64SMTkE\&t=333s
} 
Municipal da Infraestrutura, datado de julho de 2002, o município de Camocim declarou à SEMACE que a solicitação de construção do parque eólico cumpria as normas municipais de planejamento do uso da terra, orientadas pela Lei de Uso e Ocupação do Solo. No entanto, essa declaração ignorou algumas normatizações municipais, interpretando, de modo criativo, as categorias de uso da terra sem mencionar alguns aspectos óbvios da construção dos parques eólicos.

O documento municipal também indicava que o local do parque eólico era a "Praia Formosa", ajudando assim a formalizar o "apagamento cartográfico" e da identidade da comunidade da Praia de Xavier. Posteriormente, o estado oficializou esse novo topônimo com a placa da rodovia estadual indicando "Praia Formosa" (Figura 3), e emitiu mapas turísticos com o novo nome geográfico.

Figura 3 - Sinalização vertical instalada pelo Governo do Estado do Ceará com o topônimo "Praia Formosa"

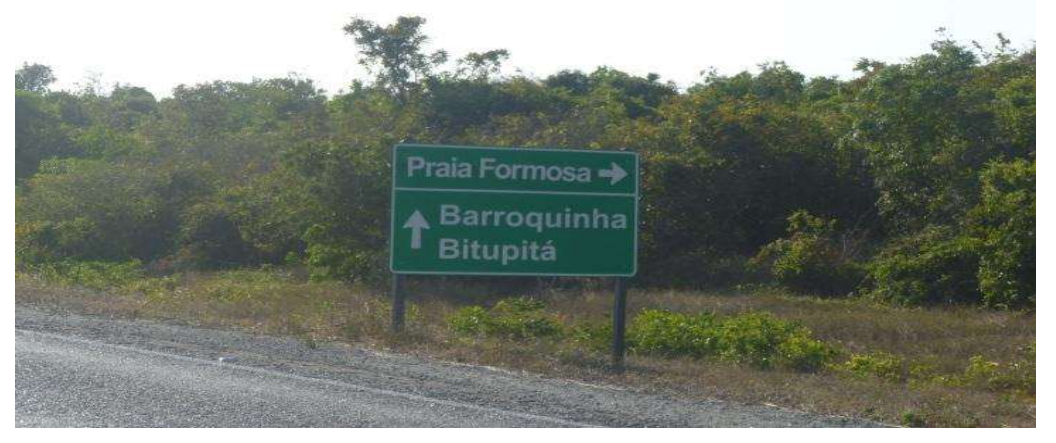

A sinalização vertical instalada pelo Governo do Estado do Ceará com o topônimo "Praia Formosa", invisibiliza a "Praia de Xavier." Esta placa foi retirada, por anônimos, ainda no ano de 2011, talvez como forma de manifestação contrária ao processo de apagamento da comunidade, e foi prostrada ao lado da rodovia, próximo à vegetação marginal. Atualmente, não é mais possível visualizá-la.

Fonte: GORAYEB, A. Outubro (2011).

Além de atrair parques eólicos para áreas de preservação ambiental em sistemas costeiros e convencer as autoridades estaduais a aprovar licenças, o processo de invisibilização da comunidade promovido pelo RAS, incluindo o "apagamento cartográfico", teve um papel importante no fomento à oposição da comunidade em relação ao parque. Isto pode ser observado na fala dos moradores de Xavier, cujo sentimento de impotência e debilidade transparece durante 
entrevista na fala: "Vi o mapa deles mostrando que ninguém morava aqui, que era terra abandonada".

Outro entrevistado lembrou que "eles deram o nome de Praia Formosa, como se ninguém morasse aqui. Então eu disse a eles [representante do parque eólico]: 'Eu sei que você não é cego e pode ver casas e pessoas aqui. Como você pode passar por nós sem saber que moramos aqui? ' Eles poderiam ter conversado conosco, mas acabamos nos tribunais". O trecho faz referência à negociação com autoridades judiciais que resultou em uma medida compensatória que é discutida na sequência.

Conflitos e políticas de compensação ambiental na Praia de Xavier

Desafios legais envolvendo líderes comunitários, uma representante de uma organização ligada à Igreja Católica e o Ministério Público forçaram três modestas concessões do parque eólico: (1) garantia de direito de passagem pelo parque eólico para veículos que transportam crianças de Xavier à escola, assim como para trânsito de outros veículos, porém, com autorização prévia; (2) oferecimento de programas curtos destinados às mulheres e crianças, como mostras de vídeos infantis e oficinas de artesanato; (3) permissão da passagem da energia (postes e fios) para chegar a Xavier, já que a comunidade não possuía eletricidade até mais de um ano depois da construção do parque eólico. Por um breve período, o parque eólico enviou representantes para melhorar a aceitação da comunidade, exibindo filmes para as crianças e oferecendo presentes durante datas comemorativas (Dia das Mães, Dia dos Pais e Dia das Crianças).

No entanto, muitos moradores da comunidade estavam insatisfeitos com a capacidade dessas políticas mitigarem impactos negativos, que incluíam insegurança alimentar resultante da perda de lagoas interdunares, como a Lagoa do Ferreira, uma fonte importante de peixe no segundo semestre do ano. O parque eólico e a Associação Comunitária de Xavier negociaram um acordo, supervisionado pelo Ministério Público, no qual o parque eólico "doaria" 540.000 reais, em 2013, à associação comunitária de Xavier para a construção de 22 casas de alvenaria, uma por família.

O uso da habitação como política de mitigação em Xavier foi o primeiro registrado no Ceará. No estado da Bahia, as empresas eólicas realocaram famílias que moravam a menos de 300 metros de uma turbina eólica ou de uma infraestrutura relacionada, pagando uma taxa única pela 
casa e construindo uma nova casa para os moradores deslocados. Casas de alvenaria, consideradas um sonho entre os moradores, destinavam-se a substituir suas casas de taipa (pau-a-pique), feitas de materiais de origem local. A associação comunitária, composta por pescadores que raramente vendiam seus peixes para pessoas de fora e que não tinham economia interna monetária, foi subitamente responsável pela construção de quase duas dúzias de casas em um local que não tinha comércio, água encanada e nenhuma via de acesso.

Até 2015 foram construídas 22 casas de tijolos com instalações básicas (Figura 4), além de um centro comunitário. Ainda assim, devido a uma gestão improvisada dos recursos por pescadores, quase em sua totalidade analfabetos ou com parca educação formal (em geral, somente até a primeira etapa do ensino fundamental), faltaram fundos financeiros para pintar as casas e realizar uma auditoria básica das despesas com um profissional de contabilidade. A dissidência na comunidade começou quando foi debatido o tamanho e o projeto de cada casa, incluindo discussões sobre o tipo de material de construção, acabamento das portas e janelas e possível construção de uma igreja católica. Os projetos foram feitos de forma improvisada, e as construções, que duraram mais de um ano, passaram por diversas fases problemáticas, incluindo fraudes de prestadores de serviços, cancelamentos e alterações diversas dos projetos (exclusão do prédio da igreja e inclusão de um prédio para a associação comunitária) e projeções de custos mal definidas.

Figura 4 - Casas de alvenaria construídas na comunidade da Praia de Xavier, Camocim, com recursos advindos de políticas compensatórias da empresa de energia eólica.

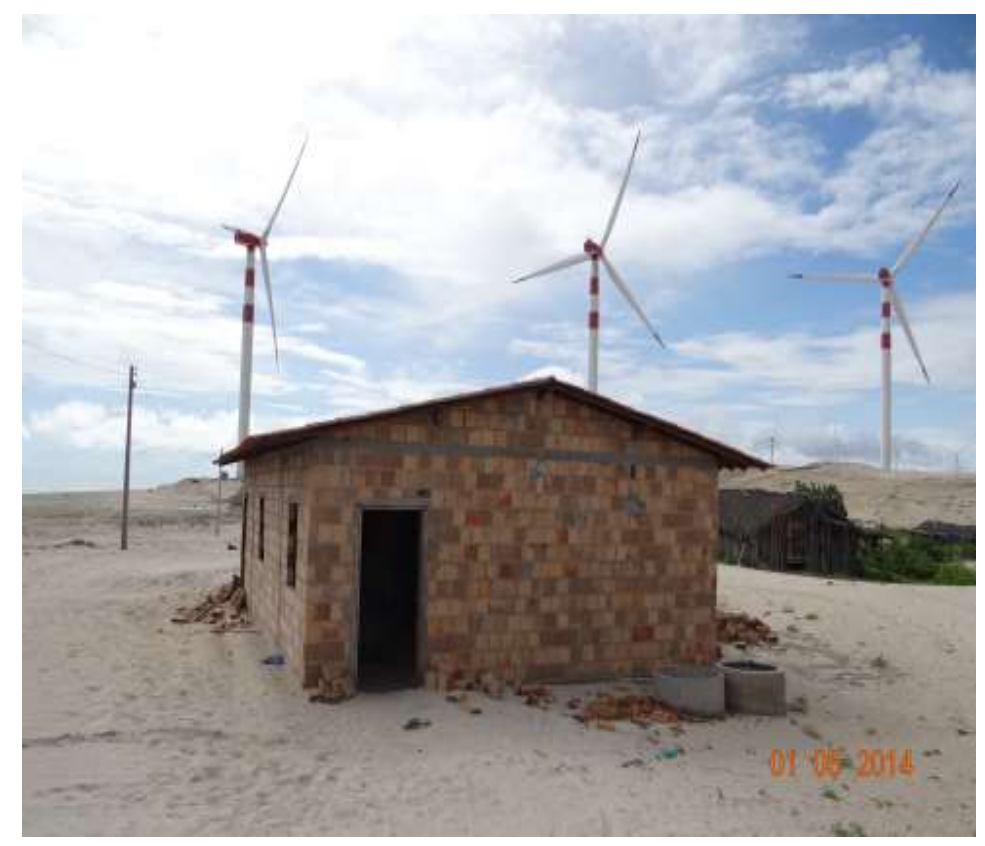

Fonte: BRANNSTROM, C. Maio (2014). 
A desconfiança entre os residentes aumentou com relação ao trabalho humanitário ligado à igreja católica, que supervisionava a construção, enquanto a chegada de trabalhadores externos criava suspeitas mútuas na comunidade. Pequenos roubos, inéditos antes da construção das casas, exacerbavam a desconfiança. Ao mesmo tempo, surgiram conflitos entre vizinhos, levando à formação de um grupo contrário à liderança da associação que intermediou o acordo de mitigação junto à empresa.

Foram observados argumentos entre os moradores relacionados aos conflitos internos, além de acusações de roubo e até ameaças de morte. A desconfiança entre moradores e trabalhadores continuou após a conclusão das casas, levando a uma atmosfera generalizada de medo e desconfiança entre as famílias, corroendo a coesão social relativamente alta que ajudou os líderes, inicialmente, a garantirem as políticas compensatórias.

Um exemplo específico de resultados indiretos observados é que alguns moradores começaram a argumentar a favor da privatização da terra por meio das falas: "Agora que tenho uma casa de alvenaria, quero vender o terreno com a casa de taipa". Esse sentimento é conhecido por abrir caminho para a venda de terrenos para pessoas de fora, o que provavelmente iniciará um processo observado muitas vezes no litoral cearense: especulação de terras, construção de grandes resorts, perda de valores tradicionais da comunidade, migração permanente de jovens e a realocação de residentes mais velhos para longe da costa, a sotavento de dunas ou perto de manguezais.

O processo de mudança também incluiu o abandono das atividades pesqueiras tradicionais, proliferação do uso de drogas e álcool e a disseminação da prostituição, inclusive a infantil. Um mau planejamento governamental, a alta exclusão social, o desemprego, a moradia precária e a baixa escolaridade colocam crianças e adolescentes em maior risco de prostituição e uso de drogas (SILVA; ÁVILA, 2010). Desde a década de 1990, o Ceará e outros estados do nordeste do Brasil são incluídos no turismo sexual internacional (RIBEIRO, 2013), observado diariamente em muitas comunidades costeiras do Ceará.

O turismo sexual tem sido uma preocupação recorrente entre os líderes comunitários das vilas de pescadores cearenses, incluindo Xavier. Em Canoa Quebrada, por exemplo, uma cidade costeira a $150 \mathrm{~km}$ a leste de Fortaleza, Schärer (2003) mostrou grande preocupação entre os moradores sobre o aumento do crime, uso de drogas e prostituição após o aumento do turismo e da chegada de visitantes, principalmente turistas estrangeiros. Situação semelhante existe em 
Jericoacoara, uma praia $50 \mathrm{~km}$ a oeste de Xavier, onde Molina (2007) atribuiu o aumento da prostituição e uso de drogas ao aumento de visitantes nacionais e internacionais, especialmente o comércio e uso do crack (subproduto de menor valor da pasta de cocaína), notadamente pelos nativos.

Vale ressaltar que alguns entrevistados, particularmente os que compunham a liderança da associação, viram a construção das casas como uma tentativa fraca de resolver um problema muito mais profundo. Um morador admitiu que "as [novas] casas são boas, mas eles [o parque eólico] não fizeram isso porque queriam; eles fizeram isso por causa dos tribunais", referindo-se ao envolvimento do Ministério Público nas tratativas. Outro entrevistado disse: " $a$ empresa reconheceu seus erros e nos deu dinheiro para essas pequenas casas, mas uma casa não chega nem perto do que eles fizeram e continuam fazendo", uma referência à destruição das dunas (e a mobilização constante de sedimentos com máquinas para limpeza da estrada principal, assoreando as residências à jusante) e ao soterramento das lagoas interdunares, que removeu uma fonte de pesca significativa para os moradores e criou insegurança alimentar.

Outro resultado indireto da mitigação foi o colapso político do interesse da comunidade em desenvolver uma Reserva Extrativista (RESEX), retratado na tese de doutorado de Mendes (2016). A criação de RESEX tem sido o meio preferido para proteger as comunidades tradicionais no Brasil contra ameaças externas (SANT'ANA JUNIOR; SILVA, 2010), em especial de grandes projetos privados (Nordeste) e governamentais (Amazônia). No entanto, após a construção das moradias, a maior parte das famílias ficou satisfeita com suas casas e o momento político de definição da RESEX arrefeceu, surgindo um sentimento maior de desconfiança e amargura contra os líderes comunitários e a participação da igreja no processo.

A partir de 2018, a comunidade de Xavier iniciou outra tentativa de garantir sua permanência no território, com apoio da universidade pública, de organizações não governamentais e da Defensoria Pública da União, mediante a outorga do Termo de Autorização de Uso Sustentável (TAUS), conferida em caráter transitório e precário pela Superintendência do Patrimônio da União (SPU) (BRASIL, 1998; 2010). Este novo passo rumo à tentativa de garantir sua permanência no território, de modo mais vulnerável e incerto, teve como pressuposto o abandono de centenas de hectares utilizados para o extrativismo (vegetal e animal, como mariscagem) e pesca continental (lagoas interdunares), em privilégio à demarcação das áreas comuns de plantio e moradia. 
A comunidade buscou o TAUS de uma fração de seu território original como forma de garantir às futuras gerações território mínimo de sobrevivência, em vista das atuais ameaças retratadas na possível ampliação do parque eólico já instalado, assim como no avanço de loteamentos irregulares nas áreas de manguezal, de especuladores vindos de praias mais distantes e com alto grau de desenvolvimento do turismo.

\section{CONCLUSÕES}

As elites locais usaram a invisibilização física e cartográfica da Praia de Xavier para tornar pessoas e recursos naturais ocultos, influenciando diretamente na aprovação de licenciamento ambiental para o maior parque eólico do Brasil, à época de sua construção. Neste processo, uma política de mitigação da empresa de energia eólica teve consequências nocivas à comunidade, sugerindo a necessidade de considerar com mais cuidado como os moradores que vivem próximos aos parques eólicos devem ser compensados pelos impactos negativos.

Este estudo de caso mostra os problemas ocorridos nas políticas de fomento à energia eólica no nordeste do Brasil, destacando questões relacionadas à precariedade fundiária (com a falta de posse segura das terras pelas comunidades de pescadores tradicionais) e à fragilidade dos sistemas judiciais para garantir os direitos dos moradores das comunidades tradicionais.

Tal processo tende a avançar a partir de 2019 devido às ações e tentativas constantes do governo federal atual em emplacar políticas fundiárias criminosas, inconstitucionais e antidemocráticas desde o início do mandato: (i) anistia à grilagem; (ii) congelamento da reforma agrária, das demarcações das terras indígenas e quilombolas e da criação de unidades de conservação; (iii) redução de dezenas de unidades de conservação já existentes (algumas com mais de 40 anos de existência); (iv) criação de legislação que permita a mineração em terras indígenas, assim como agricultura mecanizada e pecuária extensiva; (v) politização e ideologização de todo o processo de demarcação de terras (reforma agrária, indígena, quilombola e unidades de conservação); (vi) criminalização dos movimentos sociais; (vii) tentativa de transferência da demarcação de terras indígenas da FUNAI (Fundação Nacional do Índio) para o Ministério da Agricultura; (viii) tentativa de fundir o Ministério do Meio Ambiente com o Ministério da Agricultura; (ix) nomeação do presidente da Fundação Palmares, que se opõe publicamente ao movimento negro e às suas pautas de reivindicações; e $(x)$ congelamento da criação de novas 
unidades de conservação (APÓS..., 2019; QUADROS, 2019; STACHEWSKI, 2019; MAISONNAVE, 2020).

Em relação à energia eólica comunitária, uma possível solução para os conflitos (TOKE et al., 2008), ainda é uma perspectiva distante no Brasil porque as comunidades possuem poucos recursos financeiros e a política nacional (financiamento, licenciamento etc.) favorece as grandes empresas. Porém, várias políticas e práticas poderiam reduzir os conflitos relacionados à energia eólica no Ceará e em outras regiões do Nordeste, como o estabelecimento de ferramentas legais para regular o desenvolvimento de parques eólicos nas escalas estaduais e municipais, especialmente atualizando as leis municipais de zoneamento territorial, como o instrumento do Zoneamento Ecológico Econômico Costeiro (CABRAL, 2020), atualmente em construção no Estado. A criação de um processo de zoneamento transparente, que identifique áreas nas quais os projetos de energia renovável são mais compatíveis com os assentamentos humanos e a utilização de recursos, poderia evitar conflitos antes que eles surgissem, o que proporcionaria oportunidades aos moradores afetados para expressar preocupações acerca da atividade. Além disso, o desenvolvimento de Estudos de Impacto Ambiental fundamentados em princípios de disseminação e participação do público comunicaria melhor as informações do projeto de energia renovável aos membros da comunidade.

Adicionalmente, a criação de políticas de educação permanentes e a promoção de boas práticas de relação com as comunidades aumentariam a confiança entre empresas eólicas e residentes afetados. Essas políticas e práticas poderiam ajudar os parques eólicos a alcançarem a aceitação da comunidade e a lucratividade almejada no modelo de negócio. Entretanto, os empreendedores provavelmente precisarão ignorar as elites locais que tendem a usar a energia eólica para perseguir objetivos contraditórios, com base na exploração dos moradores locais e na perpetuação de práticas que disseminam a injustiça processual e distributiva.

O enfoque geográfico no território nacional sobre a expansão das energias renováveis pode melhor contribuir para a descarbonização da geração de energia com justiça socioambiental (distributiva e processual), com estudos de caso que revelem as falhas e as injustiças do processo de implantação dos projetos de energia, no sentido de perseguirmos, enquanto sociedade, uma descarbonização com justiça.

Apesar do posicionamento técnico de que os grandes desafios científicos da energia eólica sejam nos campos da engenharia de materiais, ciência atmosférica e integração nos sistemas de transmissão elétrica (VEERS et al., 2019), existem evidências abundantes de que a aceitação 
social, ou o social gap, constituem um desafio de magnitude igual ou maior do que o da engenharia e das ciências físicas (SOVACOOL, 2009; RAND; HOEN, 2017). O olhar geográfico, nos aspectos territoriais com abordagem de social gap, pode apoiar os estudos que procurem contribuir para uma descarbonização justa e apropriada ao contexto brasileiro e, em similaridade, ao dos países do Sul Global.

\section{AGRADECIMENTOS}

À Coordenadoria de Aperfeiçoamento em Nível Superior (CAPES), pelo apoio financeiro no período da pesquisa através do Projeto PGPSE/ CAPES (Proc. 88887.115970/2016-01), intitulado "Sistemas Ambientais costeiros e ocupação econômica do Nordeste".

À CAPES PRINT (Proc. 88887.312019/2018-00): Integrated socio-environmental technologies and methods for territorial sustainability: alternatives for local communities in the context of climate change.

À CAPES COOPBRAS (Proc. 88881.368924/2019-01): "Energia renovável e descarbonização na América do Sul: caminhos e desafios que conectam o setor argentino de lítio e os parques eólicos brasileiros".

\section{REFERÊNCIAS}

ABEEÓLICA. Associação Brasileira de Energia Eólica. Boletim anual de geração eólica 2018. São Paulo: Abeeólica, 2019.

AGÊNCIA NACIONAL DE ENERGIA ELÉTRICA (Brasil) (ANEEL). Sistema de informações de geração da ANEEL SIGA. Disponível em: https://app.powerbi.com/view?r=eyJrIjoiNjc4OGYyYjQtYWM2ZC00YjllLWJ1YmEtYzdkNTQ1 MTc1NjM2IiwidCI6IjQwZDZmOWI4LWVjYTetNDZhMi05MmQ0LWVhNGU5YzAxNzBIMS IsImMiOjR9. Acesso em: 01 dez. 2019.

AGÊNCIA NACIONAL DE ENERGIA ELÉTRICA (Brasil) (ANEEL). Atlas de energia elétrica do Brasil. Brasília: ANEEL, 2005. Disponível em: $<$ http://www2.aneel.gov.br/arquivos/pdf/livro_atlas.pdf>. Acesso em: 01 dez. 2019.

AMARANTE, O. A. C. et al. Atlas do potencial eólico brasileiro. Brasília: Ministério de Minas e Energia; Rio de Janeiro: Eletrobrás, 2001. 
APÓS decisão da justiça, governo suspende nomeação do presidente da Fundação Palmares. G1, 12 de dezembro de 2019.2 Disponível em: https://g1.globo.com/politica/noticia/2019/12/12/governo-suspende-nomeacoes-dos-presidentesda-fundacao-palmares-e-iphan.ghtml. Acesso em: 15 fev. 2020.

AQUILA, G. et al. An overview of incentive policies for the expansion of renewable energy generation in electricity power systems and the Brazilian experience. Renew. Sustain. Energy Rev, v.70, p. 1090-1098, 2017.

ARAÚJO, M. S. M.; FREITAS, M. A. V. Acceptance of renewable energy innovation in Brazil: case study of wind energy. Renew. Sustain. Energy Rev, v. 12, n. 02, p. 584-591, 2008.

ARAÚJO, J. C. H. As tramas da implementação da energia eólica na zona costeira do Ceará: legitimação e contestação da “energia limpa”. 2015. 185p. Dissertação (Programa de PósGraduação em Planejamento Urbano e Regional) - Universidade Federal do Rio de janeiro, Rio de Janeiro, 2015.

BAXTER, J. Energy justice: participation promotes acceptance. Nat. Energy, v. 2, p. 1-2, 2017.

BAXTER, J.; MORZARIA, R.; HIRSCH, R. A case-control study of support/opposition to wind turbines: perceptions of health risk, economic benefits, and community conflict. Energy Policy, v. 61, p. 931-943, 2013.

BELL, D.; GRAY, T.; HAGGETT, C. The 'social gap' in wind farm siting decisions: Explanations and policy responses. Environ. Politics, v. 14, n. 4, p. 460-477, 2005.

BELL, D. et al. Re-visiting the 'social gap': Public opinion and relations of power in the local politics of wind energy. Environ. Politics, v. 22, n. 1, p.115-135, 2013.

BOYER, D. Energopolitics: wind and power in the anthropocene. Durham: Duke University Press, 2019. 280p.

BRANNSTROM, C. et al. Is Brazilian wind power development sustainable? Insights from a review of conflicts in Ceará state. Renew. Sustain. Energy Rev, v. 67, p. 62-71, 2017.

BRANNSTROM, C.; TRALDI, M. Princípios e fundamentos das geografias da energia: perspectivas da geografia anglo-americana. In: GORAYEB, A.; BRANNSTROM, C.; MEIRELES, A. J. A. (edit.). Impactos socioambientais da implantação dos parques de energia eólica no Brasil. Fortaleza: Edições UFC, 2019, p. 13-24.

BRANNSTROM, C. et al. Perspectivas geográficas nas transformações do litoral brasileiro pela energia eólica. Rev. Bras. Geogr., v. 63, n. 1, p. 03-28, 2018. 
BRASIL. Conselho Nacional do Meio Ambiente. Resolução n 279, de 27 de julho de 2001. Brasília, DF: Ministério do Meio Ambiente, 2001. Disponível em: http://www.mma.gov.br/port/conama/res/res01/res27901.html. Acesso em: 03 fev. 2020.

BRASIL. Ministério do Meio Ambiente. Resolução n 462, de 24 de julho de 2014. Brasília, DF: Ministério do Meio Ambiente, 2014. Disponível em: http://www.mma.gov.br/port/conama/legiabre.cfm?codlegi=703. Acesso em: 03 fev. 2020.

BRASIL. Superintendência do Patrimônio da União (SPU). Portaria $\mathbf{n}^{\circ}$ 89, de 15 de abril de 2010. Brasília, DF: Ministério da Economia, 2010. Disponível em: http://www.mpf.mp.br/atuacao-tematica/ccr6/documentos-epublicacoes/docs/docs_outros_documentos/Portaria_SPU_89_2010.pdf/view. Acesso em: 03 fev. 2020.

BRASIL. Lei n 9636, de 15 de maio de 1998. Brasília, DF: 1998. Dispõe sobre a regularização, administração, aforamento e alienação de bens imóveis de domínio da União, altera dispositivos dos Decretos-Leis nos 9.760/1946, e 2.398/1987, regulamenta o §2o do art. 49 do Ato das Disposições Constitucionais Transitórias, e dá outras providências. Disponível em: https://www2.camara.leg.br/legin/fed/lei/1998/lei-9636-15-maio-1998-367785-

publicacaooriginal-1-pl.html. Acesso em: 10 fev. 2020.

BRASIL. Ministério de Minas e Energia. Empresa de Pesquisa Energética (EPE). Plano decenal de expansão de energia 2029. Brasília: MME/EPE, 2019. Disponível em: http://www.epe.gov.br/pt/publicacoes-dados-abertos/publicacoes/plano-decenal-de-expansao-deenergia-2029. Acesso em: 01 dez 2019.

BREUKERS, S.; WOLSINK, M. Wind power implementation in changing institutional landscapes: An international comparison. Energy Policy, v. 35, n. 5, p. 2737-2750, 2007.

CABRAL, B. Zoneamento costeiro deverá aumentar segurança jurídica no CE, DIÁRIO DO NORDESTE, 24 de janeiro de 2020. Disponível em: https:/diariodonordeste.verdesmares.com.br/ editorias/negocios/zoneamento-costeiro-deveraaumentar-seguranca-juridica-no-ce-1.2202704. Acesso em: 10 fev. 2020.

CAMARGO SCHUBERT ENGENHEIROS ASSOCIADOS. Atlas eólico e solar: Ceará. Curitiba: Camargo Schubert Engenheiros Associados; Fortaleza: ADECE, FIEC, SEBRAE, 2019. Disponível em: http://atlas.adece.ce.gov.br/. Acesso em: 03 fev. 2020. 
CAPPELLÁN-PÉREZ, I.; CASTRO, C.; ARTOD, I. Assessing vulnerabilities and limits in the transition to renewable energies: land requirements under 100\% solar energy scenarios. Renew. Sustain. Energy Rev, v. 77, p. 760-782, 2017.

CHAVES, L.; BRANNSTROM, C.; SILVA, E. V. S. Energia eólica e a criação de conflitos: ocupação dos espaços de lazer em uma comunidade no nordeste do Brasil, Sociedade e Território, v. 29, n. 2, p. 46-69, 2017.

DANTAS, E. J. A. et al. Wind power on the brazilian northeast coast, from the Whiff of Hope to turbulent convergence: the case of the Galinhos Wind Farms, Sustainability, v. 11, n. 14, p. 3802, 2019.

DE JONG, P. et al. Integrating large scale wind power into the electricity grid in the Northeast of Brazil. Energy, v.100, p. 401-415, 2016.

DEVINE-WRIGHT, P. Beyond NIMBYism: toward an integrated framework for understanding public perceptions of wind energy. Wind Energy, v. 8, n. 2, p. 125-139, 2005.

DEVINE-WRIGHT, P.; HOWES, Y. Disruption to place attachment and the protection of restorative environments: A wind energy case study. J. Environ. Psychol., v. 30, p. 271-280, 2010.

DUNLAP, A. Renewing destruction: wind energy development, conflict and resistance in a Latin American context. New York: Rowman and Littlefield, 2019. 214p.

FAST, S. Qualified, absolute, idealistic, impatient: dimensions of host community responses to wind energy projects. Environ Plan A, v. 47, n. 7, p. 1540-1557, 2015.

FAST, S. et al. Lessons learned from Ontario wind energy disputes. Nature Energy, 2016.

FILGUEIRAS, A.; SILVA, T. M. V. Wind energy in Brazil: present and future. J Renew Sustain Ener, v. 7, n. 5, p. 439-451, 2003.

FRATE, C. A. et al. Procedural and distributive justice inform subjectivity regarding wind power: A case from Rio Grande do Norte, Brazil, Energy Policy, v. 132, p. 185-195, 2019.

GEOCONSUlt CONSUlTORIA GEOLOGIA E MEIO AMBIENTE. Relatório Ambiental Simplificado - RAS da Central Eólica Praia Formosa, Camocim - CE. Fortaleza: Geoconsult Geologia, Consultoria e Meio Ambiente Ltda, 2002.

GORAYEB, A. et al. Wind power gone bad: critiquing wind power planning processes in northeastern Brazil. Energy Res. Soc. Sci, v. 40, p. 82-88, 2018. 
Revista de Geografia (Recife) V. 37, N . 3, 2020

GORAYEB, A., BRANNSTROM, C. Caminhos para uma gestão participativa dos recursos energéticos de matriz renovável (parques eólicos) no nordeste do Brasil. Mercator, v.15, p. 101$115,2016$.

GLOBAL WIND ENERGY COUNCIL (GWEC). Global Wind report: annual market update 2018. Brussels: Global Wind Energy Council, 2019.

HORST, D. NIMBY or not? Exploring the relevance of location and the politics of voiced opinions in renewable energy siting controversies. Energy Policy, v. 35, n. 5, p. 2705-2714, 2007. HOWE, C. Ecologics: wind and power in the anthropocene. Durham: Duke University Press, 2019.

JUÁREZ, A. A. et al. Development of the wind power in Brazil: political, social, and technical issues. Renew. Sustain. Energy Rev, v. 39, 828-34, 2014.

JUARÉZ-HERNANDÉZ, S.; LEÓN, G. Energía eólica en el istmo de Tehuantepec: desarrollo, actores y oposición social. Probl Desarro, v. 178, n. 45, p. 139-162, 2014.

LIEBE, U.; BARTCZAK, A; MEYERHOFF, J. A turbine is not only a turbine: the role of social context and fairness characteristics for the local acceptance of wind power. Energy Policy, v. 107, p. 300-308, 2017.

MAISONNAVE, F. Bolsonaro anistia grilagem, freia novas áreas indígenas e estaciona reforma agrária. Folha de São Paulo, 04 de janeiro de 2020. Disponível em: https://www1.folha.uol.com.br/poder/2020/01/bolsonaro-anistia-grilagem-freia-novas-areasindigenas-e-estaciona-reforma-agraria.shtml. Acesso em: 15. Fev. 2020.

MEIRELES, A. J. A. et al. Socio-environmental impacts of wind farms on the traditional communities of the western coast of Ceará, in the Brazilian Northeast. In: CONLEY, D.C. et al. (org.). Proceedings of the 12th international coastal symposium. J Coast Res, Special Issue, n. 65, p. 81-86, 2013.

MENDES, J. S.; GORAYEB, A.; BRANNSTROM, C. Diagnóstico participativo e cartografia social aplicados aos estudos de impactos das usinas eólicas no litoral do Ceará: o caso da Praia de Xavier, Camocim. Geosaberes, v. 6, n. 3, p. 243-254, 2016.

MENDES, J. S. Parques eólicos e comunidades tradicionais no Nordeste brasileiro: estudo de caso da comunidade de Xavier, litoral oeste do Ceará, por meio da abordagem ecológica/participativa. 2016. 162p. Tese (Programa de Pós-Graduação em Geografia) Universidade Federal do Ceará, Fortaleza, 2016. 
MILLER, L. M.; KEITH, D. W. Observation-based solar and wind power capacity factors and power densities. Environ. Res. Lett, v. 13, 2018.

. Corrigendum: observation-based solar and wind power capacity factors and power densities. Environ. Res. Lett, v. 14, 2019.

MOLINA, F. S. Turismo e produção do espaço: o caso de Jericoacoara, CE. 2007. 150p. Dissertação (Programa de Pós-Graduação em Geografia Humana) - Universidade de São Paulo, São Paulo, 2007.

MULVANEY, D. Solar power: innovation, sustainability, and environmental justice. Berkeley: University of California Press, 2019, p. 329.

NERI, M. et al. Green versus green? Adverting potential conflicts between wind power generation and biodiversity conservation in Brazil. Perspect Ecol Conser, v. 17, p. 131-135, 2019.

PASQUALETTI, M. J. Opposing wind energy landscapes: a search for common cause. Ann Assoc Am Geogr, v. 101, n. 4, p. 907-917, 2011 a.

PASQUALETTI, M. J. Social barriers to renewable energy landscapes. Geogr Rev, v. 101, n. 2, 201-223, 2011b.

QUADROS, V. Quem é Nabhan Garcia, o todo-poderoso secretário fundiário de Bolsonaro. EXAME, São Paulo, 10 de novembro de 2019. Disponível em: https://exame.abril.com.br/brasil/quem-e-nabhan-garcia-o-todo-poderoso-secretario-fundiario-debolsonaro. Acesso em: 14 fev. 2020.

RAND, J.; HOEN, B. Thirty years of North American wind energy acceptance research: what have we learned? Energy Res. Soc. Sci, v. 29, p. 135-148, 2017.

RIBEIRO, F. M. V. Turismo sexual na cidade de Fortaleza, estado do Ceará, e sua interface com a exploração sexual de crianças e adolescentes e com o tráfico de pessoas. In: INSTITUTO DE ESTUDOS DO GÊNERO UFSC. Seminário Internacional Fazendo Gênero, 10, 2013, Florianópolis. Anais [...]. Disponível em: http://www.fg2013.wwc2017.eventos.dype.com.br/resources/anais/20/1384879123_ARQUIVO_F ernandaMariaVieiraRibeiro.pdf. Acesso em: 01 dez. 2019.

RUEDA, E. C. Eólicos e inversión privada: el caso de San Mateo del Mar, en el Istmo de Tehuantepec Oaxaca. J Lat Am Caribb Anthropol, v. 16, n. 2, p. 257-277, 2011.

SANT'ANA JUNIOR, H. A.; SILVA, S. C. Taim: conflitos socioambientais e estratégias de defesa do território. REPOCS, v. 7, n. 13, p. 159-172, 2010. 
SCHEIDEL, A.; SORMAN, A. H. Energy transitions and the global land rush: ultimate drivers and persistent consequences. Glob. Environ. Change, v. 22, p. 588-595, 2012.

SCHARER, R. Turismo sustentável: um estudo de caso sobre a experiência da comunidade de prainha do Canto Verde no litoral do Ceará. PASOS. Revista de Turismo y Patrimonio Cultural, v. 1, n. 2, p. 231-242, 2003.

SHAW, K. et al. Conflicted or constructive: exploring community responses to new energy developments in Canada. Energy Res. Soc. Sci., v. 8, p. 41-51, 2015.

SILVA, T. A.; ÁVILA, M. A. 2010. Turismo sexual e exploração sexual infantil: uma análise da atuação do programa sentinela em Ilhéus. PASOS. Revista de Turismo y Patrimonio Cultural, v. 8, n. 1, p. 185-193, 2010.

SLATTERY, M.; LANTZ, E.; JOHNSON, B. L. State and local impacts from wind energy projects: Texas case study. Energy Policy, v. 39, p. 7930-7940, 2011.

SOBRAL, V. Operação Marambaia: 11 condenados por crime ambiental. O Povo online, Fortaleza, 03 de dezembro de 2014. Disponível em: https://www20.opovo.com.br/app/opovo/cotidiano/2014/12/03/noticiasjornalcotidiano,3357067/op eracao-marambaia-11-condenados-por-crime-ambiental.shtml. Acesso em: 01 dez. 2019.

SOVACOOL, B. K. Rejecting renewables: the socio-technical impediments to renewable electricity in the United States. Energy Policy, v. 37, p. 4500-4513, 2009.

SOVACOOL, B. K. et al. Energy decisions reframed as justice and ethical concerns. Nature Energy, v. 1, 2016.

SOVACOOL, B. K.; RATAN, P. L. Conceptualizing the acceptance of wind and solar energy. Renew. Sust. Energ. Rev, v. 16, p. 5268-5279, 2012.

STACHEWSKI, A. L. Bolsonaro mantém Ministério do Meio Ambiente, mas esvazia pasta, Época Negócios, 22 de janeiro de 2019. Disponível em: https://epocanegocios.globo.com/Brasil/noticia/2019/01/ bolsonaro-mantem-ministerio-do-meioambiente-mas-esvazia-pasta.html. Acesso em: 14 fev. 2020.

TANKHA, S. Lost in translation: interpreting the failure of privatisation in the Brazilian electrical power industry. J Lat Am Stud, v. 41, n. 1, p. 59-90, 2009.

TOKE, D.; BREUKERS, S.; WOLSINK, M. Wind power deployment outcomes: how can we account for the differences? Renew. Sust. Energ. Rev, v. 12, p. 1129-1147, 2008. 
TRALDI, M. Acumulação por despossessão: a privatização dos ventos para a produção de energia eólica no semiárido brasileiro. 2019. 378p. Tese (doutorado) - Universidade Estadual de Campinas, Instituto de Geociências, Campinas, SP, 2019.

VEERS, P. et al. Grand challenges in the science of wind energy. Science, v. 366, 2019.

WALKER, C.; BAXTER, J. "It's easy to throw rocks at a corporation": wind energy development and distributive justice in Canada. J. Environ. Policy Plan, v. 19, n. 6, p. 754-768, 2017 a.

- Procedural justice in Canadian wind energy development: A comparison of community-based and technocratic siting processes. Energy Res. Soc. Sci., v. 29, p. 160-169, $2017 b$.

WALKER, C.; BAXTER, J.; OUELLETTE, D. Beyond rhetoric to understanding determinants of wind turbine support and conflict in two Ontario, Canada communities. Environ. Plan A, v. 46, p. 730-745, 2014.

WARREN, C. R. et al. 'Green on green': Public perceptions of wind power in Scotland and Ireland. J. Environ. Plan. Manag., v. 48, p. 853-875, 2005.

WARREN, C. R.; MCFAYDEN, M. Does community ownership affect public attitudes to wind energy? A case study from south-west Scotland. Land Use Policy, v. 27, p. 204-13, 2010.

WOLSINK, M. Wind power implementation: The nature of public attitudes: Equity and fairness instead of 'backyard motives'. Renew Sust Energ Rev, v. 11, n. 6, p. 1188-1207, 2007.

. Near-shore wind power-protected seascapes, environmentalists' attitudes, and the technocratic planning perspective. Land use policy, v. 27, n. 2, p. 195-203, 2010.

WOLSINK, M.; BREUKERS, S. Contrasting the core beliefs regarding the effective implementation of wind power: an international study of stakeholder perspectives. J. Environ. Plan. Manag, v. 53, p. 535-58, 2010.

ZÁRATE-TOLEDO, E.; PATIÑO, R.; FRAGA J. Justice, social exclusion and indigenous opposition: a case study of wind energy development on the Isthmus of Tehuantepec, Mexico.

Energy Res. Soc. Sci, v. 54, p. 1-11, 2019. 